\title{
Cancer Patients' Symptom Burden and Health-related Quality of Life (HRQoL) at Tertiary Cancer Center from 2006 to 2013: A Cross-sectional Study
}

\author{
KRISTIINA KOKKONEN ${ }^{1}$, TIINA TASMUTH ${ }^{2}$, JUHO T. LEHTO ${ }^{3}$, HANNU KAUTIAINEN ${ }^{4}$, \\ ANNELI ELME ${ }^{2}$, ANNA-STINA JÄÄSKELÄINEN ${ }^{2}$ and TIINA SAARTO ${ }^{2}$ \\ ${ }^{1}$ Orton Oy and Faculty of Medicine, University of Helsinki, Helsinki, Finland; \\ ${ }^{2}$ Helsinki University Hospital, Comprehensive Cancer Center, \\ Department of Palliative Care and Faculty of Medicine, University of Helsinki, Helsinki, Finland; \\ ${ }^{3}$ Department of Oncology, Palliative Care Unit, Tampere University Hospital and \\ Faculty of Medicine and Life Sciences, University of Tampere, Tampere, Finland; \\ ${ }^{4}$ Primary Health Care Unit, Finland and Folkhälsan Research Center, \\ Kuopio University Hospital, Helsinki, Finland
}

\begin{abstract}
Background/Aim: To observe changes in symptoms and health-related quality of life (HRQoL) over 7 years among cancer patients at different stages of the disease. Patients and Methods: This prospective crosssectional study at the Helsinki University Hospital Cancer Center, was carried out in 2006 and repeated in 2013. All participants filled in the EORTC-QLQ-C30 questionnaire. Results: Altogether, 581 patients responded (49\% in 2006 and $54 \%$ in 2013). The disease was local in $51 \%$ and advanced in $49 \%$ of patients. The HRQoL was significantly lower, except for emotional and cognitive functions, and the symptom burden more severe in advanced cancer. The most prevalent symptoms were fatigue $(93 \%$ and $85 \%$; moderate/severe $22 \%$ and $9 \%)$, pain $(65 \%$ and $47 \%$; moderate/severe $16 \%$ and $5 \%$ ), and insomnia (64\% and $60 \%$; moderate/severe 20 and $21 \%$ ), respectively. No changes in HRQoL or symptoms were found at 7 years. Conclusion: There is a need for early integrated palliative care to improve HRQoL during cancer treatments.
\end{abstract}

Quality of life is a multi-dimensional concept. It reflects the ways in which a person's emotional, social, and physical aspects influence well-being in everyday life. Health-related quality of life (HRQoL) indicates how disease, disability, or

Correspondence to: Kristiina Kokkonen, MD, Orton oy, University on Helsinki, Helsinki, Finland. Tel: +358 503215287, e-mail: Kristiina.kokkonen@helsinki.fi

Key Words: Health-related quality of life, neoplasms, symptoms, palliative care. disorder affects the individual's well-being over time (1). Cancer and its treatments altogether affect patient's HRQoL in many ways.

In recent years, the survival of cancer patients has improved due to advances in cancer-specific therapies (2, $3)$. More patients are treated with intense protocols over extended periods of time. Alongside improvements in survival, it is important to maintain HRQoL (4). There is some evidence of cancer patients' symptom burden and decreasing HRQoL during oncological treatments (5-12). More than two-thirds of cancer patients with advanced disease are symptomatic $(5,6,13)$. During the last decades, palliative care has been recognized as an elementary part of cancer care throughout the cancer disease trajectory in many cancer centers to improve quality of life of cancer patients (14-19). Already in the early stages of cancer, there is a need for palliative care and psycho-oncological follow-up $(8,9,20)$.

Due to prolonged survival and various new treatment options, the symptom burden of cancer patients has changed. Previous data have mainly relied on clinical trials focusing on new cancer treatments and their adverse effects. The HRQoL related to the symptom burden has been the primary endpoint only in a few studies $(1,11)$. Real-life data concerning the symptom prevalence and HRQoL during cancer treatments are required to elucidate the need for earlier palliative and supportive care. The aims of this study were i) to observe the symptom burden and HRQoL among cancer patients in different stages of the disease treated at a tertiary cancer center in a prospective cross-sectional study design and ii) to investigate whether there is any change in the symptom burden or HRQoL over a 7-year period. 
Enrolment 2006:

\begin{tabular}{|c|c|}
\hline $\begin{array}{l}\text { Eligible patients } \mathbf{N}=\mathbf{4 4 1} \\
\text { 1. Radiotherapy depar } \\
\text { 2. Outpatient Unit: } 12 \\
\text { 3. Inpatients : } 55 \text { (12) }\end{array}$ & $\begin{array}{l}\text { (\%) } \\
\text { tment: } 263(60) \\
3(28)\end{array}$ \\
\hline $\begin{array}{l}\text { Responders } \mathbf{N}=\mathbf{2 1 5}(\mathbf{4 9}) \\
\text { 1. Radiotherapy depa } \\
\text { 2. Outpatient Unit: } 75 \\
\text { 3. Inpatients : } 38 \text { (18) }\end{array}$ & $\begin{array}{l}\text { tment: } 102 \text { (47) } \\
\text { (35) }\end{array}$ \\
\hline $\begin{array}{l}\text { Not reached or not resp } \\
\text { 1. Radiotherapy depar } \\
\text { 2. Outpatient Unit: } 48 \\
\text { 3. Inpatients : } 17 \text { (8) }\end{array}$ & $\begin{array}{l}\text { onded } \mathbf{N}=\mathbf{2 2 6}(\mathbf{5 1}) \\
\text { tment: } 161(71) \\
\text { (21) }\end{array}$ \\
\hline
\end{tabular}

Enrolment 2013:

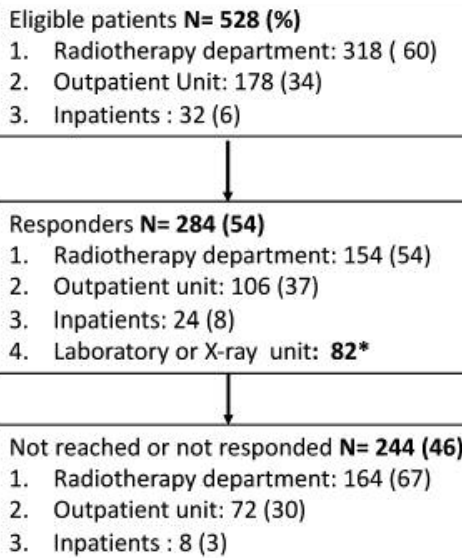

* not included in the responce rate as the total number of patients visiting laboratory or X-ray units were not available, but included in the analyses of the results

Figure 1. Flow diagram of the participants enrolment.

\section{Patients and Methods}

This study was carried out at the Cancer Center of Helsinki University Central Hospital (HUCH) as a one-day cross-sectional study performed on 31.11.2006 and 15.5.2013. The same study design was in both study sections. The study was open to all inpatients hospitalized in the oncology department and to all ambulatory patients who visited the outpatient unit or radiotherapy department during the predefined days. The exclusion criteria in 2006 were age under 16 years, trial patients, patients visiting the palliative care unit, or cancer survivors, and in 2013, age under 16 years, patient visiting the palliative care unit, and trial patients. The study protocol was approved by the Ethics Committee of the Helsinki and Uusimaa district, and each patient gave written informed consent prior to study inclusion.

The primary outcome measurements were main symptoms and HRQoL measured by the European Organization for Research and Treatment of Cancer Quality of Life Questionnaire (EORTC QLQC30). The questionnaire was delivered together with an informed consent form to be filled out by the participant. This 30 -item questionnaire produces a global health status, five functional scales (physical, role, social, emotional, and cognitive functions), three symptom scales (fatigue, nausea/vomiting, and pain), and six single-symptom items (dyspnea, insomnia, appetite loss, constipation, diarrhea, and financial difficulties) (21). All nine EORTC QLQ-C30 multi-item dimension scales produce a score from 0 (=lowest) to 100 (=highest). The higher scores on the global and functioning scales indicate better HRQoL and functioning, while the higher scores on symptom items represent more intense symptom burden $(21,22)$. A clinically significant difference is a 10 -point change in the score (23). For single-symptom items, symptoms are scaled in the following manner: no symptoms $=0$, mild symptoms $\leq 33.33$, moderate symptoms $\leq 66.66$, and severe symptoms $\leq 100$. For pain, fatigue, and nausea/vomiting, which are multi-item symptoms, $0=$ no symptoms, $\quad 0.01-66.65=$ mild symptoms, 66.66-99.99=moderate symptoms, and $100=$ severe symptoms. Medical history and demographic data of the patients were obtained from patient records.

Statistical analysis. The characteristics of the study population were presented as means with standard deviations (SD) or as counts with percentages. The statistical significance between groups were evaluated by $t$-test, Mann-Whitney test and chi-square test. Adjusted hypothesis was evaluated using generalized linear models with appropriate distribution and link function. Models included gender and age as covariates. The normality of variables was evaluated by the Shapiro-Wilk W test. Stata 15.1, StataCorp LP (College Station, TX, USA) statistical package was used for the analyses.

\section{Results}

The enrollments in 2006 and 2013 are described in a flowchart (Figure 1). The total response rate was $51 \%$ (499/969), being 49\% (215/441) in 2006 and 54\% (284/528) in 2013 . In 2013, the 82 patients who visited the clinic only for investigations ( $\mathrm{x}$-ray, laboratory units) were not included in the response rate, as the total number of patients visiting these units was not available. But they were included in the analysis since they returned the questionnaire. Thus, the total number of patients in this study was 581 . The disease was local in 298 patients $(51.3 \%)$ and advanced in 283 patients (48.7\%). The main diagnoses were breast cancer in 229 (39\%), prostate cancer in $100(17 \%)$, gastrointestinal cancer in $74(13 \%)$, lymphoma in $53(9 \%)$, and other malignancies in $125(22 \%)$ of the patients. However, there were more 


\begin{tabular}{|c|c|c|c|c|c|c|}
\hline & \multicolumn{3}{|c|}{ Local disease } & \multicolumn{3}{|c|}{ Advanced disease } \\
\hline & $\begin{array}{c}2006 \\
\mathrm{~N}=117(\%)\end{array}$ & $\begin{array}{c}2013 \\
\mathrm{~N}=181(\%)\end{array}$ & $p$-Value & $\begin{array}{c}2006 \\
\mathrm{~N}=98(\%)\end{array}$ & $\begin{array}{c}2013 \\
\mathrm{~N}=185(\%)\end{array}$ & $p$-Value \\
\hline Female, n $(\%)$ & $65(56)$ & $126(70)$ & 0.014 & $64(65)$ & $102(55)$ & 0.098 \\
\hline Age, mean (SD) & $61(12)$ & $62(13)$ & 0.43 & $62(12)$ & $63(14)$ & 0.57 \\
\hline Diagnosis, n (\%) & & & 0.14 & & & 0.074 \\
\hline 1. Breast cancer & $58(50)$ & $100(55)$ & & $29(30)$ & $42(23)$ & \\
\hline 2. Prostate cancer & $35(30)$ & 34 (19) & & $10(10)$ & $21(11)$ & \\
\hline 3. Gastrointestinal cancer & $7(6)$ & $9(5)$ & & $26(27)$ & $32(17)$ & \\
\hline 4. Lymphoma & $4(3)$ & $5(3)$ & & $9(9)$ & $35(19)$ & \\
\hline 5. Other & $13(11)$ & $33(18)$ & & $24(24)$ & $55(30)$ & \\
\hline Bone metastases (\%) & $0(0)$ & $0(0)$ & & $34(35)$ & $54(29)$ & 0.34 \\
\hline Radiotherapy, n (\%) & $77(66)$ & $103(57)$ & 0.12 & $27(28)$ & $62(34)$ & 0.30 \\
\hline Endocrine therapy, n (\%) & $45(38)$ & $73(40)$ & 0.75 & $11(11)$ & $36(19)$ & 0.077 \\
\hline Targeted therapy, n (\%) & $9(8)$ & $19(10)$ & 0.42 & $13(13)$ & $17(9)$ & 0.29 \\
\hline Chemotherapy line, n (\%) & & & 0.42 & & & 0.043 \\
\hline None & $88(75)$ & $143(79)$ & & $28(29)$ & $94(51)$ & \\
\hline 1 & $28(24)$ & $38(21)$ & & 47 (48) & $43(23)$ & \\
\hline 2 & $0(0)$ & $0(0)$ & & $13(13)$ & $19(10)$ & \\
\hline 3 & $0(0)$ & $0(0)$ & & $7(7)$ & $13(7)$ & \\
\hline$\geq 4$ & $1(1)$ & $0(0)$ & & $3(3)$ & $16(9)$ & \\
\hline
\end{tabular}

gastrointestinal cancers $(75 \%)$ in the advanced group and breast $(69 \%)$ and prostate cancers $(69 \%)$ in the local group. Of the patients with advanced disease, 88 (31\%) had bone metastases.

Differences between the years 2006 and 2013. The patient characteristics are presented separately for local and advanced disease in Table I. No significant changes occurred in the prevalence of moderate or severe symptoms, except dyspnea, which was slightly more prevalent among patients with local disease in $2006(p=0.002)$.

No significant changes were seen in the HRQoL or main functional scales in local or advanced stages of the disease between 2006 and 2013 (Figure 2).

Differences between local and advanced cancer (pooled data of 2006 and 2013). All symptoms, except insomnia and diarrhea, were more prevalent in patients with advanced disease. The overall intensity of symptoms was low in patients with local disease, although moderate or severe insomnia occurred in $21 \%$ of the patients. Fatigue, pain, and insomnia were the most prevalent and severe symptoms in advanced disease (Table II, Figure 2).

Pain was more prevalent in patients with bone metastases $[67 / 87(77 \%)]$ than in those without metastases [117/194 $(60 \%)](p=0.007)$. The pain was moderate or severe in $21 / 87$ patients $(24 \%)$ with and in 23/194 patients (12\%) without bone metastases, respectively.
The HRQoL was significantly impaired in patients with advanced disease relative to those with local disease in global health status $(p<0.001)$, physical functioning $(p<0.001)$, role functioning $(p<0.001)$, and social functioning $(p<0.001)$. No differences were found in emotional $(p=0.065)$ or cognitive $(p=0.31)$ functioning (Table III; Figure 2).

Financial difficulties. In pooled analysis for the years 2006 and 2013, financial difficulties were more prevalent in patients with advanced disease than in those with local disease $(p=0.044)$ (Table II; Figure 2). Financial difficulties were reported by $33.0 \%$ and $26.9 \%$ (moderate or severe difficulties in $8.4 \%$ and $5.1 \%$ ) of patients with advanced and local disease, respectively (Table II). No significant changes were found between the study years (Figure 2).

\section{Discussion}

This was a cross-sectional study describing the symptom burden and HRQoL among the unselected cancer population treated at the tertiary Cancer Center at two different timepoints spaced seven years apart. In line with previous research on patients receiving active cancer treatments, fatigue, insomnia, and pain were found to be the most prevalent symptoms in both the advanced and early stages of disease (5). Likewise, the symptom burden in the present and earlier studies has been more severe among patients with advanced cancer $(5,7,8,20)$. 

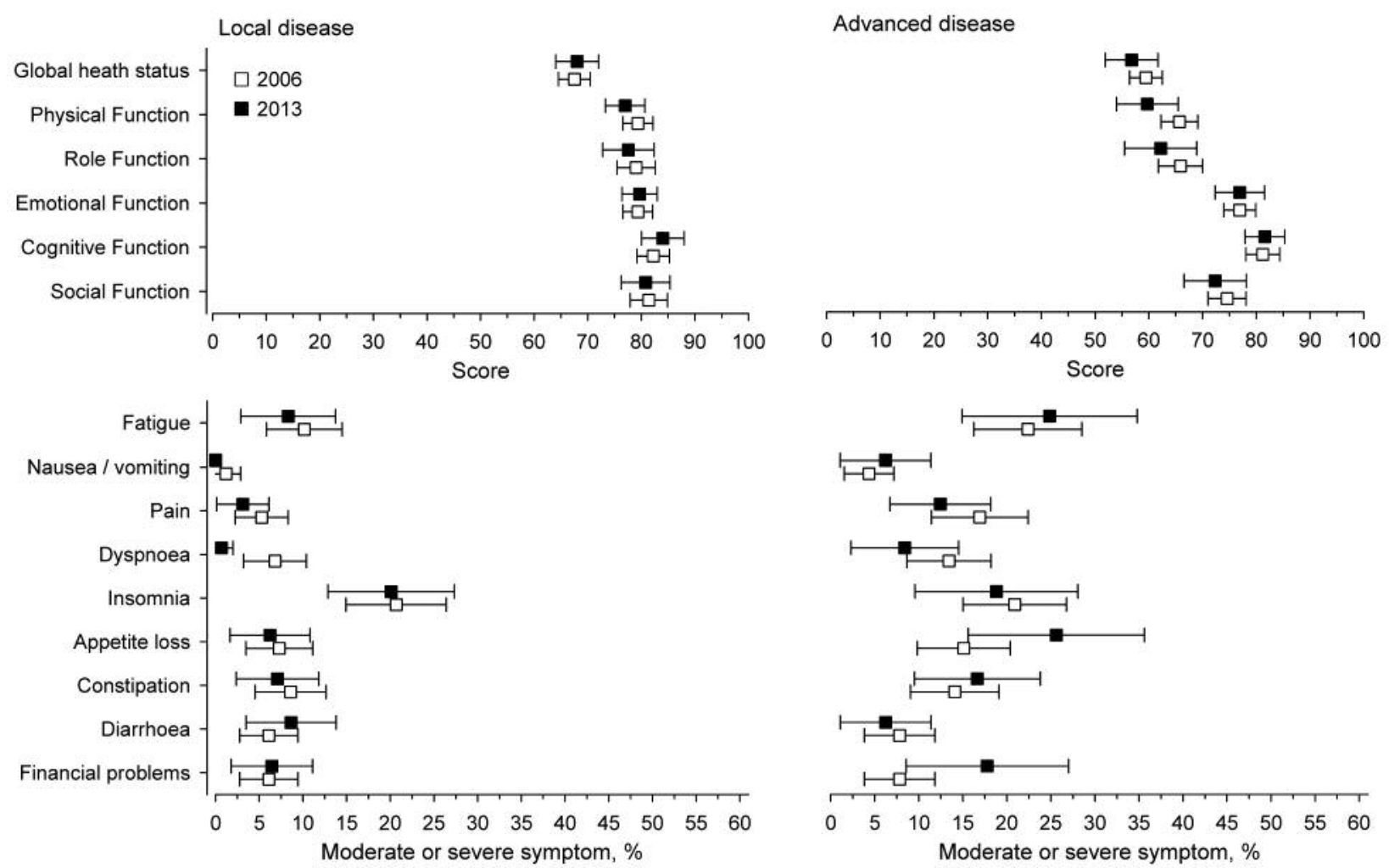

Figure 2. Health-related quality of life and prevalence of moderate or severe symptoms in patients with local and advanced disease in 2006 and 2013.

Table II. The severity of the symptoms in local and advanced disease (pooled data of year 2006 and 2013).

\begin{tabular}{|c|c|c|c|c|c|c|c|c|c|}
\hline \multirow[b]{2}{*}{ Symptoms } & \multicolumn{4}{|c|}{ Local n (\%) } & \multicolumn{4}{|c|}{ Advanced n (\%) } & \multirow[t]{2}{*}{$p$-Value* } \\
\hline & None & Mild & Moderate & Severe & None & Mild & Moderate & Severe & \\
\hline Fatigue & $44(15)$ & $227(76)$ & $23(8)$ & $4(1)$ & $19(7)$ & $198(71)$ & $55(20)$ & $7(2)$ & $<0.001$ \\
\hline Nausea & $242(81)$ & $54(18)$ & $0(0)$ & $2(1)$ & $180(64)$ & $87(31)$ & $11(4)$ & $2(1)$ & $<0.001$ \\
\hline Pain & $159(53)$ & $124(42)$ & $14(5)$ & $0(0)$ & $97(34)$ & $140(50)$ & $31(11)$ & $13(5)$ & $<0.001$ \\
\hline Dyspnea & $199(67)$ & $85(29)$ & $13(4)$ & $1(0)$ & $164(59)$ & $85(30)$ & $18(6)$ & $13(5)$ & 0.015 \\
\hline Insomnia & $118(40)$ & $116(39)$ & $54(18)$ & $10(3)$ & $101(36)$ & $123(44)$ & $46(16)$ & $11(4)$ & 0.52 \\
\hline Appetite loss & $230(78)$ & 49 (16) & $11(4)$ & $7(2)$ & $159(57)$ & $71(25)$ & $30(11)$ & $19(7)$ & $<0.001$ \\
\hline Constipation & $206(70)$ & $68(23)$ & $18(6)$ & $3(1)$ & $168(60)$ & $69(25)$ & $32(12)$ & $9(3)$ & 0.006 \\
\hline Diarrhea & $211(71)$ & $65(22)$ & $14(5)$ & $5(2)$ & $195(70)$ & $66(24)$ & $10(4)$ & $6(2)$ & 0.74 \\
\hline Financial difficulties & $215(73)$ & $64(22)$ & $10(3)$ & $5(2)$ & $184(67)$ & $68(25)$ & $17(6)$ & $6(2)$ & 0.044 \\
\hline
\end{tabular}

*Adjusted for gender and age.

Fatigue was the most prevalent symptom in our study, reported by $89 \%$ of patients, although it was mild in the majority of patients. Fatigue has been related to cancer treatments like chemotherapy $(24,25)$, but a high prevalence of fatigue has also been reported irrespectively of the therapy received. In our study, the prevalence of fatigue was significantly higher in patients with advanced disease than in those with local disease. This was probably related to the higher tumor burden and psychosocial distress among patients with advanced cancer, rather than to cancer treatments.

In our study, $56 \%$ of the patients reported pain (47\% with local and $65 \%$ with advanced disease) compared to a 
Table III. Quality of life in local and advanced disease (pooled data from years 2006 and 2013).

\begin{tabular}{lccc}
\hline & $\begin{array}{c}\text { Local mean } \\
(\text { SD })\end{array}$ & $\begin{array}{c}\text { Advanced mean } \\
(\text { SD) }\end{array}$ & $p$-Value* \\
\hline Global health status & $68(20)$ & $58(22)$ & $<0.001$ \\
Physical function & $78(20)$ & $64(25)$ & $<0.001$ \\
Role function & $78(25)$ & $64(30)$ & $<0.001$ \\
Emotional function & $79(19)$ & $77(21)$ & 0.065 \\
Cognitive function & $83(20)$ & $82(21)$ & 0.31 \\
Social function & $81(24)$ & $73(26)$ & $<0.001$ \\
\hline
\end{tabular}

*Adjusted for gender and age.

Norwegian study, where the prevalence of pain among inpatients with either local or advanced cancer varied between $53 \%$ and $55 \%$ and among outpatients between $35 \%$ and $39 \%$ (26). In the present study, moderate or severe pain was reported by $5 \%$ of patients with local disease and $16 \%$ of patients with advanced disease. The pain was more prevalent and intense among the patients with bone metastases (77\% vs. 60\%; moderate or severe pain $24 \%$ vs. $12 \%$, respectively). Thus, recent studies, including our own, show that pain remains a significant symptom among patients receiving anticancer therapies. This warrant's systematic evaluation of pain, especially in patients with bone metastases, to provide early and effective pain treatment, including palliative radiotherapy (27).

Interestingly, insomnia was frequently reported by patients, with no significant difference between individuals with local or advanced disease. Likewise, in line with previous studies of different cancer populations $(8,10,28$, 29 ), emotional and cognitive function did not differ in different stages of the disease. Thus, insomnia and emotional well-being could be related to individual coping strategies for psychosocial distress caused by cancer and treatments rather than to the stage of the disease. This highlights the need for early interventions, providing psychosocial support already in the early stage of the disease.

In our study, HRQoL was lower in patients with advanced disease than in those with local disease. The most impaired functions were the physical, role, and social domains, which is consistent with previous research $(9,12,29)$. In our earlier study on women with advanced breast cancer, pain was shown to be one of the main activity-limiting symptoms together with fatigue and depression. These three symptoms combined had a major influence on functional capacity and HRQol (10). In addition, a previous study found fatigue, depression, and physical inactivity to be the most significant factors associated with breast cancer survivors' impaired HRQoL (28). Thus, the high prevalence and intensity of fatigue, pain, and insomnia in our study could explain the significant impairment in physical, role, and social functions, especially in patients with advanced disease. Activity-limiting symptoms and functional impairment may cause physical inactivity, triggering a vicious cycle with generalized weakness and impaired HRQoL (10, $30,31)$. There is solid evidence of the benefits of cancer patients' rehabilitation during and after adjuvant treatments in terms of improved HRQoL (28, 32-36), but also some evidence among patients with advanced phase disease (10, 37). Our results highlight the need for active rehabilitation programs to be integrated into cancer center care to maintain physical and emotional well-being during ongoing treatments and follow-up.

Unexpectedly, we failed to show any significant improvement in symptom control or HRQoL during 20062013. Our findings are partly in line with a Norwegian study describing pain intensity in cancer patients treated at a tertiary cancer unit. The authors had concluded that no significant change occurred in experienced pain from 2008 to 2014 (26). There are several possible explanations for the lack of improvement in HRQoL and symptom control in our study. Firstly, even though outpatient palliative care clinics located in cancer centers play an important role in cancer patient care (14), patients are still introduced to the palliative care team at a late stage of the disease, after oncological treatments have been terminated, rather than concurrently with the cancer-centered care. However, an international consensus highlights the early introduction of patients with advanced cancer or patients with severe symptoms or suffering to the palliative care team to improve HRQoL of the patients already during the cancer-directed treatments (38). This early integration of palliative care has been shown to improve cancer patients' QoL and overall satisfaction with care $(18,19,39-41)$. Yet, during the study period there were no standards in the study center for referral to the palliative care unit early in the course of the disease. Secondly, the symptoms were not routinely assessed during the cancer treatments. This might have left patients' symptoms hidden and possibly insufficiently treated in clinical practice. Similarly, there was no systematic assessment of emotional distress or any standard procedure for referral to the psychooncological team for consultation.

Strengths of our study were the cancer-specific, commonly used and validated questionnaire and equivalent study groups in terms of sample size and the main characteristics (e.g. cancer types, ages). Thus, comparing the local and advanced disease groups was possible within the combined population. In addition, we present non-selected patient populations, thus representing the real-life situation in the cancer center. However, some limitations in our investigation must also be noted. First, the study method was cross-sectional, which prevented us from identifying any changes in symptoms or HRQoL over time. Second, the study population included heterogeneous cancer types and the total response rate remained relatively low $(49 / 54 \%)$. 


\section{Conclusion}

The symptom load was higher in patients with advanced disease during the oncological treatments, but also patients with local disease suffered from symptoms of moderate or severe intensity. No significant changes were seen during seven years in the main functional components used to assess HRQoL or in the total symptom burden of the patients treated at the tertiary cancer center. This survey highlights the need for systematic assessment of symptoms, psychological distress, and functional impairment of cancer patients in all phases of the disease. There is an ongoing need for early integrated palliative care, rehabilitation, and psycho-oncological support in order to maintain HRQoL during cancer-directed treatments.

\section{Conflicts of Interest}

The Authors declare no conflicts of interest regarding this study.

\section{References}

1 Bottomley A: The cancer patient and quality of life. Oncologist 7: 120-125, 2002.

2 Chia SK, Speers CH, D’yachkova Y, Kang A, Malfair-Taylor S, Barnett J, Coldman A, Gelmon KA, O'reilly SE and Olivotto IA: The impact of new chemotherapeutic and hormone agents on survival in a population-based cohort of women with metastatic breast cancer. Cancer 110: 973-979, 2007.

3 De Angelis R, Sant M, Coleman MP, Francisci S, Baili P, Pierannunzio D, Trama A, Visser O, Brenner H, Ardanaz E, Bielska-Lasota M, Engholm G, Nennecke A, Siesling S, Berrino F, Capocaccia R and EUROCARE-5 Working Group: Cancer survival in Europe 1999-2007 by country and age: results of EUROCARE-5-a population-based study. Lancet Oncol 15: 23-34, 2014.

4 Lin NU and Burstein HJ: EMBRACE, eribulin, and new realities of advanced breast cancer. Lancet 377: 878-880, 2011.

5 Reilly CM, Bruner DW, Mitchell SA, Minasian LM, Basch E, Dueck AC, Cella D and Reeve BB: A literature synthesis of symptom prevalence and severity in persons receiving active cancer treatment. Support Care Cancer 21: 1525-1550, 2013.

6 Singer AE, Meeker D, Teno JM, Lynn J, Lunney JR and Lorenz KA: Symptom trends in the last year of life from 1998 to 2010: a cohort study. Ann Intern Med 162: 175-183, 2015.

7 Teunissen SCCM, Wesker W, Kruitwagen C, de Haes,Hanneke C J M., Voest EE and de Graeff A: Symptom prevalence in patients with incurable cancer: a systematic review. J Pain Symptom Manage 34: 94-104, 2007.

8 Farkkila N, Torvinen S, Roine RP, Sintonen H, Hanninen J, Taari $\mathrm{K}$ and Saarto T: Health-related quality of life among breast, prostate, and colorectal cancer patients with end-stage disease. Qual Life Res 23: 1387-1394, 2014.

9 Farkkila N, Sintonen H, Saarto T, Jarvinen H, Hanninen J, Taari $\mathrm{K}$ and Roine RP: Health-related quality of life in colorectal cancer. Colorectal Dis 15: e215-22, 2013.

10 Kokkonen K, Saarto T, Makinen T, Pohjola L, Kautio H, Jarvenpaa $\mathrm{S}$ and Puustjarvi-Sunabacka $\mathrm{K}$ : The functional capacity and quality of life of women with advanced breast cancer. Breast Cancer 24: 128-136, 2017.
11 Adamowicz K: Assessment of quality of life in advanced, metastatic prostate cancer: an overview of randomized phase III trials. Qual Life Res 26: 813-822, 2017.

12 Rautalin M, Farkkila N, Sintonen H, Saarto T, Taari K, Jahkola $\mathrm{T}$ and Roine RP: Health-related quality of life in different states of breast cancer - comparing different instruments. Acta Oncol 1-7, 2017.

13 Singer AE, Goebel JR, Kim YS, Dy SM, Ahluwalia SC, Clifford M, Dzeng E, O'Hanlon CE, Motala A, Walling AM, Goldberg J, Meeker D, Ochotorena C, Shanman R, Cui M and Lorenz KA: Populations and Interventions for Palliative and End-of-Life Care: A Systematic Review. J Palliat Med 19: 995-1008, 2016.

14 Gaertner J, Siemens W, Meerpohl JJ, Antes G, Meffert C, Xander C, Stock S, Mueller D, Schwarzer G and Becker G: Effect of specialist palliative care services on quality of life in adults with advanced incurable illness in hospital, hospice, or community settings: systematic review and meta-analysis. BMJ 357: j2925, 2017.

15 Haun MW, Estel S, Rucker G, Friederich H, Villalobos M, Thomas M and Hartmann M: Early palliative care for adults with advanced cancer. Cochrane Database Syst Rev 6: 011129, 2017.

16 Kavalieratos D, Corbelli J, Zhang D, Dionne-Odom JN, Ernecoff NC, Hanmer J, Hoydich ZP, Ikejiani DZ, Klein-Fedyshin M, Zimmermann C, Morton SC, Arnold RM, Heller L and Schenker $\mathrm{Y}$ : Association between palliative care and patient and caregiver outcomes: A Systematic Review and Meta-analysis. JAMA 316 : 2104-2114, 2016.

17 Ferrell BR, Temel JS, Temin S, Alesi ER, Balboni TA, Basch EM, Firn JI, Paice JA, Peppercorn JM, Phillips T, Stovall EL, Zimmermann $\mathrm{C}$ and Smith TJ: Integration of palliative care into standard oncology care: American Society of Clinical Oncology Clinical Practice Guideline Update. J Clin Oncol 35: 96-112, 2017.

18 Jordan K, Aapro M, Kaasa S, Ripamonti CI, Scotte F, Strasser F, Young A, Bruera E, Herrstedt J, Keefe D, Laird B, Walsh D, Douillard JY and Cervantes A: European Society for Medical Oncology (ESMO) position paper on supportive and palliative care. Annals of Oncology 29: 36-43, 2018.

19 Hui D, Elsayem A, De la Cruz M, Berger A, Zhukovsky DS, Palla S, Evans A, Fadul N, Palmer JL and Bruera E: Availability and integration of palliative care at US cancer centers. JAMA 303: 1054-1061, 2010.

20 Kim Y, Yen IH and Rabow MW: Comparing Symptom Burden in Patients with Metastatic and Nonmetastatic Cancer. J Palliat Med 19: 64-68, 2016.

21 Aaronson NK, Ahmedzai S, Bergman B, Bullinger M, Cull A, Duez NJ, Filiberti A, Flechtner H, Fleishman SB and de Haes JC: The European Organization for Research and Treatment of Cancer QLQ-C30: a quality-of-life instrument for use in international clinical trials in oncology. J Natl Cancer Inst 85: 365-376, 1993.

22 King MT: The interpretation of scores from the EORTC quality of life questionnaire QLQ-C30. Qual Life Res 5: 555-567, 1996.

23 Osoba D, Rodrigues G, Myles J, Zee B and Pater J: Interpreting the significance of changes in health-related quality-of-life scores. J Clin Oncol 16: 139-144, 1998.

24 Bower JE, Ganz PA, Desmond KA, Bernaards C, Rowland JH, Meyerowitz BE and Belin TR: Fatigue in long-term breast carcinoma survivors: a longitudinal investigation. Cancer 106: 751-758, 2006. 
25 Servaes P, Verhagen S and Bleijenberg G: Determinants of chronic fatigue in disease-free breast cancer patients: a crosssectional study. Ann Oncol 13: 589-598, 2002.

26 Thronaes M, Raj SX, Brunelli C, Almberg SS, Vagnildhaug OM, Bruheim S, Helgheim B, Kaasa $S$ and Knudsen AK: Is it possible to detect an improvement in cancer pain management? A comparison of two Norwegian cross-sectional studies conducted 5 years apart. Support Care Cancer 24: 2565-2574, 2016.

27 Westhoff PG, de Graeff A, Monninkhof EM, Pomp J, van Vulpen M, Leer JWH, Marijnen CAM, van der Linden YM and Dutch Bone Metastasis Study Group: Quality of life in relation to pain response to radiation therapy for painful bone metastases. Int J Radiat Oncol Biol Phys 93: 694-701, 2015.

28 Penttinen HM, Saarto T, Kellokumpu-Lehtinen P, Blomqvist C, Huovinen R, Kautiainen H, Jarvenpaa S, Nikander R, Idman I, Luoto R, Sievanen H, Utriainen M, Vehmanen L, Jaaskelainen AS, Elme A, Ruohola J, Luoma M and Hakamies-Blomqvist L: Quality of life and physical performance and activity of breast cancer patients after adjuvant treatments. Psychooncology 20: 1211-1220, 2011.

29 Torvinen S, Farkkila N, Sintonen H, Saarto T, Roine RP and Taari K: Health-related quality of life in prostate cancer. Acta Oncol 52: 1094-1101, 2013.

30 Fialka-Moser V, Crevenna R, Korpan M and Quittan M: Cancer rehabilitation: particularly with aspects on physical impairments. J Rehabil Med 35: 153-162, 2003.

31 Stricker CT, Drake D, Hoyer KA and Mock V: Evidence-based practice for fatigue management in adults with cancer: exercise as an intervention. Oncol Nurs Forum 31: 963-976, 2004.

32 Ferrer RA, Huedo-Medina TB, Johnson BT, Ryan S and Pescatello LS: Exercise interventions for cancer survivors: a meta-analysis of quality of life outcomes. Ann Behav Med 41: 32-47, 2011

33 Swartz MC, Lewis ZH, Lyons EJ, Jennings K, Middleton A, Deer RR, Arnold D, Dresser K, Ottenbacher KJ and Goodwin JS: Effect of home- and community-based physical activity interventions on physical function among cancer survivors: A Systematic Review and Meta-Analysis. Arch Phys Med Rehabil 98: 1652-1665, 2017.

34 Penttinen H, Rautalin M, Roine R, Jahkola T, KellokumpuLehtinen P, Huovinen R, Kautiainen H, Jarvenpaa S, HakamiesBlomqvist L, Blomqvist C and Saarto T: Quality of life of recently treated patients with breast cancer. Anticancer Res 34 1201-1206, 2014
35 Saarto T, Penttinen HM, Sievanen H, Kellokumpu-Lehtinen P, Hakamies-Blomqvist L, Nikander R, Huovinen R, Luoto R, Kautiainen H, Jarvenpaa S, Idman I, Utriainen M, Vehmanen L, Jaaskelainen A, Elme A, Ruohola J, Palva T, Vertio H, Rautalahti M, Fogelholm M, Blomqvist C and Luoma M: Effectiveness of a 12-month exercise program on physical performance and quality of life of breast cancer survivors. Anticancer Res 32: 3875-3884, 2012.

36 Saarto T, Sievanen H, KellokumpuLehtinen P, Nikander R, Vehmanen L, Huovinen R, Kautiainen H, Jarvenpaa S, Penttinen HM, Utriainen M, Jaaskelainen AS, Elme A, Ruohola J, Palva T, Vertio H, Rautalahti M, Fogelholm M, Luoto R and Blomqvist C: Effect of supervised and home exercise training on bone mineral density among breast cancer patients. A 12-month randomised controlled trial. Osteoporosis Int 23: 1601-1612, 2012.

37 Cheville AL, Kornblith AB and Basford JR: An examination of the causes for the underutilization of rehabilitation services among people with advanced cancer. Am J Phys Med Rehabil 90: S27-37, 2011.

38 Hui D, Mori M, Watanabe SM, Caraceni A, Strasser F, Saarto T, Cherny N, Glare P, Kaasa S and Bruera E: Referral criteria for outpatient specialty palliative cancer care: an international consensus. Lancet Oncol 17: e552-e559, 2016.

39 Temel JS, Greer JA, El-Jawahri A, Pirl WF, Park ER, Jackson VA, Back AL, Kamdar M, Jacobsen J, Chittenden EH, Rinaldi SP, Gallagher ER, Eusebio JR, Li Z, Muzikansky A and Ryan DP: Effects of early integrated palliative care in patients with lung and GI cancer: A randomized clinical trial. J Clin Oncol 35: 834-841, 2017.

40 Zimmermann C, Swami N, Krzyzanowska M, Hannon B, Leighl N, Oza A, Moore M, Rydall A, Rodin G, Tannock I, Donner A and Lo C: Early palliative care for patients with advanced cancer: a cluster-randomised controlled trial. Lancet 383: 17211730, 2014.

41 Davis MP, Temel JS, Balboni T and Glare P: A review of the trials which examine early integration of outpatient and home palliative care for patients with serious illnesses. Ann Palliat Med 4: 99-121, 2015.
Received November 9, 2018

Revised November 21, 2018

Accepted November 27, 2018 